\title{
LO SUBLIME KANTIANO COMO PARADOJA. A PROPÓSITO DE UN EJEMPLO DE JEAN-LUC MARION
}

\author{
THE KANTIAN SUBLIME AS A PARADOX. \\ REGARDING AN EXAMPLE BY JEAN-LUC \\ MARION
}

\author{
JAIME LLORENTE CARDO* \\ IES "Campo de Calatrava" (Ciudad Real)
}

\begin{abstract}
Resumen: Partiendo de un ejemplo mencionado por Jean-Luc Marion, el presente trabajo trata de desarrollar y explicitar las conexiones entre la teoría del «fenómeno saturado» o "paradoja» expuesta por el fenomenólogo francés y la descripción del fenómeno de lo sublime que Kant ofrece fundamentalmente en su Crítica del juicio. A este respecto, se examinan los cuatro puntos de vista o categorías que permiten reconocer un determinado fenómeno como «saturado» o "paradójico" (invisable, insupportable, absolu e irregardable) a la luz del modo en el cual Kant aborda la cuestión de la exposición perceptiva a un elemento definido por la sublimidad. Tal análisis permite acaso arrojar alguna luz sobre el sentido del renacimiento «popular» de la estética de lo sublime que puede apreciarse en múltiples aspectos de la cultura contemporánea.
\end{abstract}

Palabras clave: Kant, Marion, fenómeno saturado, sublime, ilimitado.

AвSTRACT: Starting from an example mentioned by Jean-Luc Marion, the present work tries to develop and make clear the connections between the theory of the «saturated phenomenon» or "paradox» exposed by the French phenomenologist and the

" Profesor y jefe del Departamento de Filosofía. Dirección postal: Ronda de Ciruela, No 18, 5o A. 13004. Ciudad Real. E-mail: jakobweinendes@gmail.com 
description of the phenomenon of the sublime that Kant offers fundamentally in his Critique of Judgment. In this regard, the four points of view or categories that make it possible to recognize a certain phenomenon as a «saturated» or "paradoxical» one (invisable, insupportable, absolu, and irregardable) are examined in light of the way in which Kant broaches the question of the perceptive exposition to an element defined by sublimity. This analysis may shed some light on the real meaning of the "popular» rebirth of the aesthetics of the sublime that can be observed in multiple aspects of contemporary culture.

KeYwords: Kant, Marion, saturated phenomenon, sublime, unlimited

\section{Introducción: la noción de lo sublime y el fenómeno paradójico}

Si bien la categoría estética de lo sublime no goza en la actualidad de un volumen de preeminencia teórica tan apreciablemente pujante como aquel del cual disfrutaba en el contexto de los siglos XVIII y XIX en el marco de la obra de pensadores tales como Burke, Kant, Schiller o Schopenhauer, no deja de resultar igualmente cierto el hecho de que, convenientemente diluida y tamizada, conserva un nada desdeńable grado de presencia en el marco de ciertos contextos estético-culturales característicamente propios de la contemporaneidad. Esta no siempre inmediatamente apreciable huella se deja sentir en el interior de contextos tan inicialmente poco previsibles como la estética gráfica de múltiples videojuegos (Dante's Inferno constituiría al respecto un ilustrativo ejemplo), la puesta en escena visual propia de numerosos filmes y series televisivas (American Horror Story), o simplemente se halla larvadamente presente en la extendida tendencia fotográfica y videográfica a captar instantáneas que logran coagular la caída de un relámpago durante una aparatosa tormenta o a atrapar en una secuencia visual imágenes y escenas protagonizadas por violentos y destructivos tornados. En todos los fenómenos mencionados se muestran de forma explícita o tácita los vestigios de la noción de sublimidad tal como ésta resulta elucidada por Burke y en mayor medida por Kant en la «analítica de lo sublime» de su Kritik der Urteilskraft. ${ }^{1}$

${ }^{1}$ Como observa al respecto M.A. Gaete Cáceres: «Contrario a lo que se pueda pensar, lo sublime no ha dejado de formar parte de la vorágine del pensamiento actual, alzándose, especialmente desde la década del 70, como una materia recurrente en el panorama intelectual de los círculos europeo y norteamericano, recuperándose como categoría útil y válida para la 
Menor volumen de evidencia reviste el hecho de que el fenómeno de la sublimidad constituye acaso un particular tipo de fenomenicidad absolutamente divergente en cuanto a su esencia y modo de donación de todo «fenómeno corriente» $\mathrm{o}$ "de derecho común», y también radicalmente distinto a cualquier clase de «fenómeno pobre» o de "fenómeno de revelación». Estas últimas categorías pertenecen a la "tópica del fenómeno» merced a la cual Jean-Luc Marion taxonomiza y clasifica la totalidad de los posibles modos de fenomenicidad, es decir de donación de algo que comparece o se muestra ante la mirada de un sujeto perceptor receptivo. Marion reconoce en el peculiar modo de darse propio de lo sublime (tal como ello es caracterizado por la exposición kantiana) la eclosión de una clase particular y singular de fenomenicidad: aquella que resulta susceptible de ser descrita bajo el rubro de «fenómeno saturado»o «paradoja»:

Ya en la doctrina de lo sublime se trata exactamente con un fenómeno saturado, cuyas características comparte. En efecto, según la cantidad, lo sublime no tiene ni forma ni orden, puesto que es grande "[...] sin comparación", absolutamente y no comparativamente [...]. Según la cualidad, contradice el gusto en tanto que "placer negativo" y provoca un "sentimiento de desmesura", de "monstruosidad". Según la relación, lo sublime escapa muy claramente a toda analogía y a todo horizonte puesto que es literalmente lo "ilimitado [Unbegrenztheit]" lo que está representando. Finalmente, según la modalidad, lejos de concordar con nuestro poder de conocer, «puede aparecer [erscheinen mag] de modo que contradice la finalidad [zweckwidrig] de nuestra facultad de juzgar [...]. El ejemplo kantiano de lo sublime permitiría así abrir más ampliamente el campo de aplicación del concepto de fenómeno saturado (Marion, 2008, 357-358).

reinterpretación de lo social, lo político y lo artístico [...]. Esta «recuperación» de lo sublime se caracteriza por volver a examinar unas bases inscritas en la óptica kantiana y burkeana, cuestionando ahora, por ejemplo, las posibilidades de la presentación o representación de «la imagen», especialmente en relación con el tema de la angustia, el trauma y el terror [...], abriéndose una puerta de entrada para lo sublime a través de lo monstruoso y lo informe» (Gaete Cáceres, 2015, p. 40). En referencia al fenómeno de la sublimidad y del concepto estético de lo sublime en general, puede consultarse: Aullón de Haro (2006). 
Así pues, se trataría de apercibirse con claridad del hecho de que en todas aquellas ocasiones en las cuales la conciencia se halla expuesta a un espectáculo perceptivo definido por la sublimidad tiene lugar, de forma consciente o inconsciente, la experiencia de captación de un fenómeno saturado, de una paradoja. No obstante, tras su alusión ilustrativa, Marion se abstiene de desarrollar y profundizar en la forma en que el fenómeno paradójico o "saturado» conviene por esencia a la teorización kantiana acerca de lo sublime. Constituirá el objetivo del presente estudio poner detalladamente de relieve el modo concreto en que el procedimiento marioniano consistente en invertir el sentido de los cuatro modos o perspectivas de consideración de un fenómeno en los cuales se escinden las categorías kantianas coincide con la definición general de "paradoja» en cuanto modo de mostración situado al margen de todo horizonte y con independencia de remisión alguna a un Yo, esto es, a una subjetividad determinada. ${ }^{2}$ Aquellos objetos de la intuición que admiten ser incardinados en el seno de un horizonte de constitución y que se dejan sin mayores dificultades reconducir a un Yo son claramente objetos finitos, limitados, de-finidos por un hóros o límite que marca ya de entrada etimológicamente la esencia de todo hori-zonte. A esta clase de fenómenos pertenecen todos aquellos objetos susceptibles de ser calificados como «bellos». Belleza y finitud son nociones que van de consuno, la primera presupone la segunda, mientras que el objeto investido de sublimidad se localiza, inversamente, en el informe ámbito de lo ilimitado: lo carente de hóros alguno, de horizonte constitutivo y de referencia a una subjetividad constituyente. En este decisivo aspecto radica el vínculo o nexo esencial que establece la primera ligazón entre la sublimidad kantiana y el fenómeno paradójico.

El otro punto de tangencia fundamental entre ambas instancias reside en el modo en que el fenómeno saturado o paradoja se sitúa -en analogía tanto con lo bello como con lo sublime kantiano- al margen o más allá de la potencia del concepto. En el caso de lo sublime se da una sobreabundancia tal de flujo intuitivo que este desbordamiento de la aisthèsis satura y anega las facultades reflexivo-conceptuales propias del sujeto. La paradoja, pues, supone una primacía del exceso de intuición absolutamente refractaria a la posibilidad de que cualquier concepto logre adecuarse a ella. Es en este sentido que Marion se refiere a

\footnotetext{
${ }^{2}$ En palabras del propio Marion: «qu'adviendrait-il, en fait de phénoménalité, si s'accomplissait une donation intuitive absolument inconditionnée (sans les limites d' un horizon) et absolument irreductible (à un Je constituant)? Ne peut-on envisager un type de phénomène qui inverserait la condition d'un horizon (en le débordant, au lieu de s'y inscrire) et inverserait la réduction (en reconduisant á soi le Je, au lieu de s'y réduire)?» (Marion, 2010, p. 43).
} 
"la possibilité d'un phénomène oú l'intuition donnerait plus, voire démesurément plus, que l'intention n' aurait jamais visé, ni prévu", dado que "il ne s'agit plus de la non-adéquation de l' intuition (manquante) laissant vide un concept (donné); il s'agit inversement d'une défaillance du concept (manquant) laissant aveugle l'intuition (surabondamment donnée). Désormais, c'est le concept qui manque, non plus l'intuition» (2010, pp. 54-55). Esta deficiencia de lo conceptual por desmesura de lo dado a la intuición es justamente la que acontece en último término, como veremos, en el caso de la exposición al fenómeno sublime tal como ésta resulta teorizada en la tercera crítica kantiana. Procederemos, pues, examinando, a la luz de la recién mencionada definición de "paradoja» o «fenómeno saturado» cada una de las modalidades categoriales kantianas que Marion utiliza (invirtiéndolas) a la hora de caracterizar tal tipo de fenomenicidad a la luz de sus puntos de convergencia con la teorización kantiana relativa al fenómeno de lo sublime. Ello nos permitirá tanto explicitar la pertinencia de la adscripción de lo sublime kantiano a la categoría de "paradoja» (un rasgo, como hemos indicado, preterido por el propio Marion) como elucidar la significación profunda que el renacimiento, no tanto teórico como «cultural», de la estética de lo sublime en la cultura de masas actual reviste realmente y en última instancia.

\section{Una magnitud ilimitada que place negativamente}

En primer lugar, siguiendo la caracterización de Marion, la paradoja resulta invisable, es decir, «no-mentable» desde el punto de vista cuantitativo. Ello es debido a su radical imprevisibilidad. La paradoja dona ciertamente una cierta magnitud extensiva (una cantidad), pero una cantidad imprevisible la medida en que no se trata de una instancia resultante de un previo proceso de adición, esto es, del producto de un acto de síntesis sucesiva que permitiría «reconstituir la representación del todo a partir de la representación de la suma de sus partes» (Marion, 2008, 330). De esta forma, al no tratarse de un fenómeno cuantificado de este modo y conforme a tal procedimiento sintético, la paradoja se muestra como elemento refractario a resultar previsto de antemano en calidad de aggregatum. Esta imprevisibilidad suya constituye un rasgo que permite intuir ya de entrada el carácter ilimitado y carente de forma, es decir, de limes o frontera definiente que define el modo de donación excesivo del fenómeno 
saturado. ${ }^{3}$ Cuando Kant define «verbalmente» lo sublime como «aquello que es absolutamente grande», es decir, "grande por encima de toda comparación», se refiere tácitamente al carácter imprevisible de la magnitud no sintética al cual alude Marion, esto es, apunta a un exceso en cuanto al quantum considerado que no resulta susceptible de ser atribuido a un agregado de partes configurado progresivamente en virtud de un acto de síntesis sucesiva. Esta idea subyace de modo palmario a la declaración kantiana conforme a la cual:

Que algo es una magnitud (quantum), se puede conocer por la cosa misma, sin comparación alguna con otras, a saber: cuando una pluralidad de lo idéntico, juntado, constituye un uno. Pero el cómo sea de grande exige siempre otra cosa, que también es una magnitud para medirlo [...], así vemos que toda determinación de magnitud de los fenómenos no nos puede dar de ningún modo, concepto alguno absoluto de una magnitud, sino siempre un concepto de comparación (Kant, 1991, 188).

Precisamente Marion enfatiza el carácter «no-mentable» (invisable) del fenómeno paradójico indicando que los fenómenos no saturados se presentan como previsibles debido justamente a su prefiguración a partir de otros fenómenos diferentes a ellos mismos. Y ello gracias a la finitud inherente a la magnitud de cada uno de sus elementos constituyentes y a la ulterior y paralela finitud propia de la suma («el uno», diría Kant) de la totalidad de tales partes individuales; pero sucede que «esas propiedades resultan precisamente insostenibles cuando se trata del fenómeno saturado» (Marion, 2008, 330). Lo absolutamente grande lo es debido a la inexistencia de otras partes con respecto a las cuales cotejarlo y compararlo, es decir, gracias a la ausencia de una totalidad configurada conforme al paradigma de partes extra partes. La captación de la paradoja demanda, pues, al decir de Marion, no ya una síntesis sucesiva, sino una suerte de «síntesis

\footnotetext{
${ }^{3}$ Es por ello que, en consonancia con lo anteriormente apuntado, Kant escribe: «Lo bello de la naturaleza se refiere a la forma del objeto, que consiste en su limitación; lo sublime, al contrario, puede encontrarse en un objeto sin forma, en cuanto en él, u ocasionada por él, es representada ilimitación y pensada, sin embargo, una totalidad de la misma, de tal modo que parece tomarse lo bello como la exposición de un concepto indeterminado del entendimiento, y lo sublime como la de un concepto semejante de la razón» (Kant, 1991, pp. 183-184).
} 
instantánea». A esa simultaneidad contrapuesta a la adición sintética paulatina se refiere Kant cuando indica que:

Cuando el quantum es dado en la intuición, en el aprehender, se realiza sólo progresivamente (no comprensivamente) según un principio de progresión adoptado. En esta apreciación matemática de las magnitudes, si la imaginación elige como unidad una magnitud que se pueda aprehender de un golpe de vista [...], el entendimiento se encuentra tan bien servido y tranquilizado como si elige una milla alemana o todo un diámetro terrestre (Kant, 1991, 195).

Lo sublime, en tanto que fenómeno ilimitado y carente de forma aparece esencialmente, pues, como una instancia refractaria a toda tentativa de síntesis progresiva, admitiendo únicamente ser captada con absoluta simultaneidad, de modo homogéneo e inmediato mediante u simple coup d'oeil. No evidentemente en cuanto a la comprensión efectiva de su magnitud ilimitada, sino desde la perspectiva de su concreta donación «empírica» ante un sujeto perceptor en cuanto fenómeno efectivamente captado.

De esta manera, el fenómeno paradójico, se da bajo la forma del exceso, de un modo des-mesurado que torna inviable toda hipotética tentativa de medición a partir de la suma de sus partes constituyentes y que, por tanto, «se impone sin precedentes, ni partes, ni suma» (Marion, 2008, 332). Al igual que el elemento sublime, el modo de donación de la paradoja supone la exposición a un fenómeno "desbordado siempre por la intuición que lo satura», y que por ello «debería nombrarse inconmensurable, no mensurable (inmenso), desmesurado», con una desmesura nacida de "nuestra simple imposibilidad de aplicar una síntesis sucesiva que permita prever un agregado a partir de la suma finita de sus partes finitas» (Marion, 2008, 331). Los ejemplos aducidos por Kant en su opúsculo precrítico Beobachtungen über das Gefühl des Schönen und Erhabenen (1764) en relación con la esencia de la sublimidad no hacen sino confirmar el postulado entronque entre lo sublime tal como es caracterizado por el pensador de Königsberg y el carácter invisable que Marion atribuye al fenómeno saturado o paradoja. En efecto, si efectivamente «La noche es sublime, y el día es bello» (Kant, 1990b, 31 ), ello se debe sin duda al hecho de que la oscuridad nocturna pone en escena 
un elemento homogéneo, informe e internamente ilimitado que difumina hasta hacerlos desaparecer todos los límites y perfiles definidos que los objetos nítidamente determinados por la luz diurna muestran ante la mirada del observador, esto es, elimina toda forma acotada apreciable. Otro tanto sucede en referencia a la soledad ligada a lo desértico: «La soledad profunda es sublime, pero de una manera terrible. Por lo que las grandes extensiones desérticas como el enorme desierto del Schamo en Tartaria, han dado ocasión en todo tiempo para figurarse allí sombras horribles, duendes y fantasmas» (Kant, 1990b, 32-33). También en este caso se trata de una extensión cuya vastedad a ojos del contemplador resulta virtualmente ilimitada y en cuyo seno deviene ardua la tarea de establecer síntesis sucesivas o sumas de partes constituyentes, dado que la magnitud desértica se aproxima peligrosamente a la condición de elemento homogéneo, indiferenciado y amorfo, habida cuenta de su esencial simplicidad y ausencia de determinaciones variadas y claramente definidas que la constituyan.

Es por ello que el propio Kant advierte que «Lo sublime ha de ser siempre grande, lo bello puede también ser pequeño. Lo sublime ha de ser sencillo, lo bello puede ser limpio y estar adornado» (Kant, 1990b, 34). «Sencillo» significa aquí, con palmaria evidencia, «simple», es decir, no estrictamente compuesto por partes reconociblemente susceptibles de ser enumeradas, adicionadas y previstas, sino dado en forma de fenómeno desbordado por la intuición de una totalidad indivisa, ilimitada y definida por un volumen tal de unicidad que únicamente admite ser captada, efectivamente, merced a un acto de intuición instantánea. Mediante una síntesis inmediata tan simple como lo es la sencillez inherente a la instancia así aprehendida. No es de extrañar que Marion vincule el carácter no-mentable (según la cantidad) propio de la paradoja con la experiencia del asombro o étonnement. ${ }^{4}$ Efectivamente, también Kant establece una clara ligazón entre la experiencia de lo sublime y la fascinación nacida de la estupefacción y el asombro ante determinados objetos y espectáculos naturales cuando alude a «la estupefacción que confina con el miedo, el terror y el temblor sagrado que se apoderan del espectador al contemplar masas montañosas que escalan el cielo, abismos profundos donde se precipitan furiosas las aguas, desiertos sombríos que invitan a tristes reflexiones, etc.» $(1990,214-215)$. Esto vale igualmente en

\footnotetext{
${ }^{4}$ «Todo fenómeno que provoca asombro se impone a la mirada en la medida misma (o más exactamente en la desmedida) en que no resulta de ninguna adición previsible de cantidades parciales: la síntesis tiene lugar sin conocimiento completo del objeto, así pues nuestra síntesis; se libera de esta manera de la objetidad que le impondríamos, para imponernos su propia síntesis, realizada por su parte antes de que podamos reconstituirla (por tanto, síntesis pasiva)» (Marion, 2008, 331-332).
} 
referencia a esa variante de la estupefacción que es la admiración (el étonnement marioniano) Un sentimiento definido por Kant como «una estupefacción que no cesa al perderse la novedad" y que se diferencia de la estupefacción tout court en que ésta se muestra fundamentalmente como "emoción en la representación de la novedad que supera lo que se esperaba» $(1990,219)$. Estas reflexiones acerca de la ligazón existente entre el sentimiento estético de lo sublime y los fenómenos de la estupefacción y la admiración (rasgo común a Marion y Kant), nos conducen directamente al examen de los efectos de la sublimidad (y del fenómeno saturado-paradoja, según nuestra hipótesis-guía) sobre el ánimo y las facultades tanto perceptivas como emotivas propias del sujeto perceptor, es decir, a la consideración del segundo de los tipos de inversión de las categorías kantianas postulado por Marion: el relativo al punto de vista no ya cuantitativo sino relativo a la cualidad.

Contemplado desde la perspectiva de la cualidad, el fenómeno saturado o paradoja admite ser definido en virtud de su carácter «insoportable» (insupportable). En el contexto de la fenomenología marioniana de la donación el atributo «insoportable» se predica de un fenómeno en el cual la intensidad con la que en él se da la intuición adquiere tal volumen de magnitud que resulta cegadora para las facultades perceptivas del espectador: «la mirada no puede soportarla como podría ante una luz que deslumbra y quema» (Marion, 2008, 334). Así pues, la visión resulta deslumbrada, obnubilada y enceguecida por «un visible que nuestra mirada no puede sostener» al encontrarse ahíta de flujo intuitivo: saturada y desbordada por un visible que se vierte sobre ella sin medida alguna, de modo desmesurado y excesivo. Esta desmedida intensidad en la forma de darse al sujeto es la responsable de que en el caso de la exposición intuitiva a la paradoja «la gloria de lo visible pese entonces con todo su peso, es decir, pese demasiado» (2008, 335). Según el parecer de Marion, lo sublime kantiano entronca con la categoría de «insoportabilidad» en la medida en que supone una contradicción casi "parafísica» con respecto a las tendencias "naturales" propias del gusto al provocar precisamente un sentimiento de "desmesura y monstruosidad». ${ }^{5}$ En este sentido, el carácter insoportable ligado a la intuición de lo sublime se adentra ya decididamente en la esfera de los afectos y sentimientos que el exceso deslumbrante en el que la paradoja se da a ver ocasiona en el ánimo del sujeto receptor de tal desbordamiento óptico. Conforme al dictamen kantiano, al contrario que la belleza, la cual contiene esencialmente un «sentimiento de impulsión a la vida, y por tanto, puede unirse con el encanto y con una imaginación que juega», la

\footnotetext{
${ }^{5}$ Sobre este aspecto, véase: Lyotard, 1991.
} 
afección anímica provocada por la sublimidad constituye un tipo sumamente particular de sensación placentera que surge de forma indirecta:

Por medio del sentimiento de una suspensión momentánea de las facultades vitales seguida inmediatamente por un desbordamiento [término netamente vinculado al fenómeno saturado o paradójico en tanto que insupportable] tanto más fuerte de las mismas; y así, como emoción, parece ser, no un juego, sino seriedad en la ocupación de la imaginación. De aquí que no pueda unirse con encanto; y siendo el espíritu, no sólo atraído por el objeto, sino sucesivamente también siempre rechazado por él [en cuanto difícilmente soportable], la satisfacción en lo sublime merece llamarse, no tanto placer positivo como, mejor, admiración o respeto, es decir, placer negativo (Kant, 1990, 184).

El sentimiento de admiración en el cual desembocaba, como vimos, el rasgo invisable propio de la paradoja, se transmuta, pues, en este segundo momento, en una afección negativamente placentera. Mejor aún: en una panoplia de afectos comúnmente hermanados por esa paradójica y extraña mixtura entre la satisfacción ligada a lo agradable y lo inquietantemente impregnado de rasgos dolorosos, temibles e incluso abiertamente terroríficos. Esta sorprendente «satisfacción negativa» constituye el factor que torna difícilmente soportable el fenómeno de lo sublime y lo aproxima a la esfera de la paradoja marioniana. ${ }^{6}$ Parece, a esta luz, paladino que el carácter insoportable que Marion avizora en los aspectos más decididamente «desmesurados» de los cuales hace gala lo sublime kantiano se deriva directamente de la primera de las «especies de lo sublime» que Kant distinguía ya en las Beobachtungen de 1764, con manifiesta exclusión de las dos restantes. En efecto, en el mencionado opúsculo Kant escinde el fenómeno de lo sublime, aquel que «conmueve», mientras que el de lo bello más bien «encanta», en tres especies o categorías: lo «sublime-terrible», lo «sublime-noble» y «lo sublime magnífico». Así mientras que en el caso de las dos últimas, el sentimiento de

\footnotetext{
${ }^{6}$ «La satisfacción de lo sublime de la naturaleza es, por eso, también sólo negativa (mientras que la de lo bello es positiva), a saber: un sentimiento de la privación de libertad de la imaginación por sí misma, al ser ella determinada de un modo conforme a fin, según otra ley que la del uso empírico» (Kant, 1990, 214).
} 
lo sublime se presenta acompańado por una «admiración sosegada» y por «una belleza que se extiende sobre un plano sublime» respectivamente, en lo referente a lo sublime terrible (esto es, insoportable) comparece vinculado a «cierto horror o también melancolía» (Kant, 1990b, 32). Dado que se trata aquí de elucidar el sentido del fenómeno saturado desde el punto de vista de la cualidad (esto es, en tanto que «insoportable»), no es de extrañar que Kant, en consonancia con lo apuntado en referencia a la primera de las especies de lo sublime indique oportunamente que "La cualidad del sentimiento de lo sublime es que es un sentimiento de dolor [afecto difícil y penosamente soportable] sobre el juicio estético en un objeto, sentimiento que, sin embargo, al mismo tiempo es representado como conforme a fin» (Kant, 1990, 202).

Así pues, el sentimiento ocasionado por la captación del fenómeno sublime no es sino una afección dolorosa surgida a partir de la no coincidencia entre el modo en que la imaginación y la razón actúan a la hora de distinguir y estimar estéticamente una magnitud. Pero tal sentimiento de displacer y dolor se presenta siempre, en el caso de la exposición a la sublimidad, acompañado de un particular sentimiento de placer (negativo), de tal modo que «el objeto es recibido como sublime , con un placer que sólo es posible mediante un dolor» $(1990,203)$. Sucede, asimismo, que lo sublime dinámico en la naturaleza suscita en el ánimo un sentimiento de temor cuando el objeto que provoca tal sentimiento reviste un carácter nocivo o potencialmente perjudicial para nosotros y, a la vez, no hallamos entre nuestras facultades alguna investida de suficiente potencia como para hacerle frente y resistir su embate con garantías de éxito. También en este caso, pues, se trataría de una afección difícil de soportar originada además por una instancia que comparece ante nosotros en calidad de obstáculo al cual debemos oponer algún tipo de resistencia. Esto es lo que sucede, en casos de sublimidad natural como los mencionados por Kant: «rocas amenazadoras, nubes de tormenta que se amontonan en el cielo y se adelantan con rayos y truenos, volcanes en todo su poder devastador, huracanes que van dejando tras de sí la desolación, el océano sin límites rugiendo de ira, una cascada profunda en un río poderoso, etc.» Sin embargo, el volumen de atracción y admiración que tales espectáculos sublime-naturales son capaces de suscitar resulta directamente proporcional al grado de miedo y pavor que efectivamente producen. Tal satisfacción negativa constituye el factor que permite reconocer el elemento sublime como objeto de respeto, mientras que, por contraposición, consiente identificar el sentimiento de lo bello con una afección nacida a partir del encanto. Este último no necesita, pues, ser soportado ni experimentado como obstáculo al cual oponer resistencia, mientras que la impresión de respeto, temor, miedo y dolor que se halla 
aherrojada al sentimiento de lo sublime sí precisa de cierto esfuerzo del ánimo a la hora de resultar tolerada y asimilada por el sujeto perceptor.

Todas las mencionadas formas de "placer negativo» asociadas a la experiencia de lo sublime suponen, pues, otros tantos modos de contradicción del gusto que, al decir de Marion, emparentarían la noción kantiana de lo sublime con su propio concepto de «fenómeno saturado»o «paradoja» en tanto que contemplado desde el prisma cualitativo, esto es, en cuanto elemento insupportable. No obstante es aquí, tal vez, donde el postulado paralelismo entre sublimidad y paradoja resulta en mayor medida susceptible de ser puesto en tela de juicio o, al menos, levemente matizado. En efecto, ello sucede desde el punto y hora en que el fenómeno saturado marioniano refulge con tal volumen de pujanza e intensidad que resulta insoportable en sentido radical para la visión, es decir, que colma de tal modo la facultad óptica que ocasiona privación de la contemplación, ablepsia, ceguera e incapacidad para continuar simplemente representando el objeto paradójico así aprehendido. De hecho, en palabras del propio Marion:

La magnitud intensiva de la intuición, cuando llega a dar un fenómeno saturado, no puede soportarse con la mirada, de igual manera que esa mirada no podía prever tampoco su magnitud extensiva. Cuando no puede soportar lo que ve, la mirada experiencia un deslumbramiento [...]. Se trata, en efecto, de un visible que nuestra mirada no puede sostener; se experimenta ese visible como insostenible para la mirada porque la colma sin medida» $(2008,334-335){ }^{7}$

Con todo, la sublimidad kantiana, a pesar de suponer un obstáculo que opone resistencia a la mirada y a la vez la demanda por parte del sujeto percipiente, siempre resulta soportable para la intuición, la cual, al margen de los sentimientos de temor, dolor o respeto que el sujeto pueda experimentar en su exposición al espectáculo sublime, logra mantenerse en todo momento en pie

\footnotetext{
${ }^{7}$ Algo que también sucede curiosamente en el caso del Ser heideggeriano: «Aquella transparencia de lo siempre obvio sin trasfondo da una claridad en la que el ojo del saber es deslumbrado hasta la ceguera» (Heidegger, 2008, 180).
} 
sin que su actividad resulte interrumpida por un volumen excesivamente intenso de sobresaturación perceptiva.

De este modo, los espectáculos propios de la sublime natural en su variante dinámica (tormentas, erupciones volcánicas, etc.) no dejan de resultar captados y de placer negativamente siempre y cuando, apunta Kant, «nos encontremos nosotros en lugar seguro» (Kant, 1990, 204), es decir, con tal de que no tenga efectivamente lugar esa característica excitación de la voluntad que se produce cuando existe la conciencia de un elemento amenazador investido de capacidad efectiva para resultar, como diría Aristóteles en referencia al sentimiento del phóbos, phthartikôu hé lypèroû: "perjudicial» $\mathrm{y}$ "dañino» o "penoso». ${ }^{8}$ Lo sublime kantiano no genera, pues, tanto un deslumbramiento tal que «señala un carácter universalizable respecto a toda forma de intuición de una intensidad tal que rebasa el grado que una mirada puede sostener» (Marion, 2008, 337), cuanto, más bien, una cierta sobreexcitación de las facultades intuitivas y emotivas que en ningún momento alcanza el paroxismo que la haría devenir insoportable de facto o verdaderamente insostenible para las facultades intuitivas del observador. Ciertamente, lo sublime aparece, conforme a la definición kantiana, como un elemento que "place inmediatamente por su resistencia contra el interés de los sentidos» (Kant, 1990, 213), es decir, tal como lo expresa Marion, que "contradice el gusto en tanto que placer negativo", pero el sentimiento de "desmesura» $\mathrm{y}$ «monstruosidad» que acompaña a su percepción es siempre susceptible de continuar siendo contemplado sin que las facultades visuales del individuo resulten real y verdaderamente colmadas y desbordadas, esto es, en último término, canceladas de modo efectivo temporalmente (al menos mientras dura la exposición intuitiva al objeto sublime).

Quizá el análisis marioniano admita únicamente ser aplicado a fenómenos sublimes de carácter ilimitado, simple, homogéneo e informe tales como la oscuridad nocturna absoluta (un ejemplo de sublimidad aducido por el propio Kant), dado que en casos como este no es posible aducir el rasgo de «hallarnos en lugar seguro» o en la disposición anímica de un contemplador representativo meramente «externo». Ello sucede en la medida en que se presupone aquí la presencia envolvente del elemento sublime que en este caso sí envuelve e incluye en sí la totalidad de la presencia individual del sujeto perceptor que se halla, por así decirlo, efectivamente sumido y colmado por su objeto de percepción.

${ }^{8}$ Reth., B, 1382a, 22. 


\section{Un absoluto que se despliega contra las condiciones de toda experiencia}

El tercer punto de vista adoptado por Marion en referencia a los rasgos esenciales de la paradoja -siguiendo en todo momento el hilo conductor de la inversión de las categorías kantianas, y tras el examen de la cantidad y la cualidad- no es otro que el alusivo a la categoría de relación. Desde la perspectiva de la relación el fenómeno saturado se presenta como «absoluto», lo cual significa "hurtado» o «refractario» a toda analogía de la experiencia o, lo que viene a ser equivalente, sustraído esencialmente a «la representación de una necesaria conexión entre las percepciones» que torna posible toda experiencia en general. Tal conexión es la contenida en las tres categorías kantianas de la relación: inherencia y subsistencia (relación entre el accidente y la sustancia), causalidad y dependencia (relación entre efecto y causa) y comunidad (acción recíproca entre varias sustancias agentes y pacientes). En el caso de la descripción kantiana de lo sublime como aquello absolutamente grande en lo que «es representada ilimitación» $(1990,183)$ e indeterminación en referencia a un elemento hipotéticamente carente de forma, resulta ciertamente dificultoso aplicar las categorías de inherencia y subsistencia, En efecto, ¿cuál sería en este marco -en el de la absoluta oscuridad o en el de lo absolutamente desértico y despoblado, por ejemplo- el elemento susceptible de hacer las veces de sustancia sobre la cual inhiriese accidente alguno? ¿Y qué clase de elementos accidentales cabría distinguir en el seno de un magnitud ilimitada y homogénea dotada de una magnitud tan extensa que no admite comparación alguna con otras magnitudes, esto es, «no aplicable a ningún juicio lógico matemáticamente determinado, sino sólo al juicio estético de la magnitud» (Kant, 1990, 189)?

Dígase otro tanto en referencia a la relación de causalidad. ¿De qué modo se verificaría la conexión entre una causa actuante y un efecto resultante de ella en el interior de la esfera de la absoluta magnitud y la Unbegrenztheit ligadas a lo informe y carentes de determinaciones concretas y definidas? Más aún: ¿qué clase de "acción recíproca» o Wechselwirkung cabe avizorar en el indeterminado y simple ámbito de un elemento -como señalamos en referencia a lo invisable según la cantidad- no constituido por la síntesis y adición de partes constituyentes? ¿Qué forma habría de revestir una hipotética relación de actividad-pasividad mutua acontecida en el marco de un todo no compuesto de partes extra partes sino único y homogéneo? Un todo que además resulta únicamente susceptible de ser captado en virtud de "un único golpe de vista» y sólo mediante al uso de 
una síntesis no sucesiva sino, como indica expresamente Marion, simultánea. ¿No presupone acaso la relación de causalidad, también la referente a la acción recíproca entre sustancias, la prioridad y posterioridad (el prius de la causa actuante y el posterius del efecto resultante de ella) características de la sucesión y que se hallan por definición excluidas de todo fenómeno dado con simultaneidad? Todas las cuestiones recién indicadas desembocan en un auténtico naufragio de la totalidad de las categorías kantianas de relación tal como éstas son presentadas en la exposición de la deducción kantiana de los conceptos puros del entendimiento, del mismo modo en que, en el caso de lo invisable, las categorías cuantitativas de pluralidad y totalidad (en tanto que formada por adición sucesiva de partes) fueron ya sometidas a un severo marasmo. Desde esta perspectiva, el fenómeno sublime escapa a toda analogía de la experiencia y se presenta, por tanto, como independiente de toda necesidad en cuanto a los nexos cognoscitivos que posibilitan la percepción empírica, esto es, como «absoluto».

Con todo, tal vez la cuarta y última de las perspectivas que hemos de examinar, aquella relativa a la modalidad y contemplada desde la cual el fenómeno paradójico aparece como irregardable o «inmirable», resulte la revestida en mayor medida de pregnancia de entre todas las inversiones marionianas de las categorías. Al menos cuando resulta aplicada, como ha ocurrido con las tres restantes, al fenómeno de lo sublime kantiano. "Inmirable» se dirá, según Marion, aquel objeto que no concuerda con nuestras facultades cognoscitivas, que no se conforma armónicamente con nuestro "poder de conocer». En caso de que un fenómeno "no "concordara" y no "correspondiera" con el poder de conocer del $Y o$ », sugiere Marion invocando precisamente a Kant, entonces «un tal fenómeno simplemente no aparecería; o más bien, no habría ningún fenómeno» (2008, 349). Sin embargo, en el caso del fenómeno saturado o paradoja se da la singular situación de que la subjetividad experimenta el hiato, la disconformidad y la desavenencia entre el fenómeno y las condiciones de experiencia que el sujeto le opone, no resultando, pues, el Yo capaz de constituir adecuadamente el objeto y de representarlo del modo habitual, ${ }^{9}$ y, no obstante, esta impotencia en cuanto a la objetivación y constitución efectiva de un determinado fenómeno, lejos de ocasionar la no aparición de este (su imposibilidad fenoménica), provoca una desmesura y sobreabundancia en la intuición por mor de la cual el fenómeno «para-empírico» «se impone a título de fenómeno excepcional por exceso, no por

\footnotetext{
${ }^{9}$ «Determinar el fenómeno saturado como inmirable equivale a aceptar que se impone a la vista con un tal exceso de intuición que ya no puede reducirse a las condiciones de la experiencia (a la objetidad), así pues, al Yo que las fija» (Marion, 2008, 351).
} 
defecto. El fenómeno saturado no se deja mirar como un objeto, precisamente porque aparece con un exceso múltiple e indescriptible que anula todo esfuerzo de constitución» $(2008,349,350)$.

Esto es precisamente lo que sucede también en el caso de la exposición intuitiva al fenómeno de lo sublime kantiano. En primer lugar, como fue ya señalado, lo sublime, conforme al dictamen de Kant, "place inmediatamente por su resistencia contra el interés de los sentidos». Desde luego, el principal y prioritario interés de todo sentido (fundamentalmente el de la visión) reside en la tendencia ínsita en él a objetivar, esto es, a constituir de forma nítida un objeto y representarlo en tanto que fenómeno determinado y claramente reconocible. La intuición de lo sublime alza serios escollos ante esta pretensión cognoscitiva fundamental y, en principio, indispensable, dado que el carácter placentero derivado de su aprehensión visual hunde sus raíces justamente en el modo en que el fenómeno dado con sublimidad contradice y obstaculiza esa esencial tendencia interesada que late tras toda facultad sensorial. ${ }^{10}$ Así pues, como apuntaría Marion, el fenómeno sublime se da como una suerte de "contra-experiencia», en contradicción con las posibilidades de toda experiencia en general, pero con una sobresaturación intuitiva desbordante y desmesurada que logra a pesar de ello mantenerse en cuanto elemento intuido e incluso a constituirse en elemento capaz de placer negativamente. Lo sublime, podría decirse pues, admite ser visto pero resulta refractario a ser mirado. De este modo:

El fenómeno saturado contradice las condiciones subjetivas de la experiencia precisamente en esto: no se deja constituir como un objeto [...], aunque ejemplarmente visible, el fenómeno saturado no se deja mirar. El fenómeno saturado se da en tanto que resulta, según la modalidad, inmirable [...], se trata de poder mantener (garder) lo visible visto de una manera bajo el control del que mira, de ejercer ese control manteniendo lo visible en su visibilidad, tanto como sea posible (Marion, 2008, 350).

\footnotetext{
${ }^{10}$ Por decirlo con M. Kuplen, "Kant's explanation of the sublime raises the question as to why is it the case that even though both sublime and ugly objects are disordered and ill-adapted to our cognitive abilities, producing thereby the feeling of displeasure» (Kuplen, 2015, 118).
} 
Lo sublime kantiano responde perfectamente a tal caracterización en la medida en que la ilimitación a la que apunta desborda nuestras facultades cognoscitivas, anega la potencia del concepto tanto como las capacidades intuitivas de nuestra visión y, no obstante, continúa mostrándose y ocasionando ese sentimiento de respeto que nace, según nuestra hipótesis, del modo en que violenta $\mathrm{e}$ impugna la voluntad constituyente propia de nuestra sensibilidad sin hurtarnos por ello totalmente la captación del espectáculo ofrecido por el fenómeno sublime. ${ }^{11}$ El propio Kant establece una esencial distinción entre belleza y sublimidad apelando precisamente al criterio del mayor o menor volumen de concordancia y conveniencia entre la finalidad ligada a nuestro juicio cuando escribe:

La belleza natural (la independiente) parece ser una finalidad en su forma, mediante la cual el objeto parece, en cierto modo, ser determinado de antemano para nuestro juicio; en cambio, lo que despierta en nosotros, sin razonar, sólo en la aprehensión, el sentimiento de lo sublime, podrá parecer, según su forma, desde luego, contrario a un fin para nuestro Juicio, inadecuado a nuestra facultad de exponer y, en cierto modo, violento para la imaginación; pero sin embargo, sólo por eso será juzgado tanto más sublime (Kant, 1990, 184).

En nuestro contexto, el hecho de que el objeto parezca hallarse «determinado de antemano para nuestro juicio» significa simplemente que admite ser previsto y constituido por el Yo; es lo que sucede en el caso de los objetos determinados y nítidamente perfilados que el Yo constituye sin obstáculo alguno y que son susceptibles de ser apreciados como bellos. Por su parte, el que el modo de donación de lo sublime acaezca al margen de toda conceptualización («sin razonar») y derive de un elemento dado meramente a la intuición de modo

\footnotetext{
${ }^{11}$ A este respecto, Terry Eagleton observa lo siguiente: «En presencia de la belleza, experimentamos una exquisita sensación de adaptación de la mente a la realidad; pero ante la presencia turbulenta de lo sublime recordamos forzosamente los límites de nuestras empequeñecidas imaginaciones y somos advertidos de que no nos es posible conocer el mundo como una totalidad infinita. Es como si en lo sublime lo "Real» como tal -la eterna e inabarcable totalidad de las cosas- quedara marcado como el límite de precaución de toda ideología, de toda la complaciente centralidad del sujeto, y nos llevara a sentir el dolor de la imperfección y del deseo insatisfecho» (Eagleton, 2011, 148-149).
} 
inmediato e instantáneo («sólo en la aprehensión»), muestra hasta qué punto se trata aquí de algo que satura la facultad intuitiva del sujeto con un exceso óptico tan contra-empírico como aconceptual. De ahí el que el sentimiento suscitado por la sublimidad se presente como "contrario a un fin para nuestro juicio", es decir, como un exceso inmirable que no admite ya ser reconducido a las condiciones de nuestra experiencia ni de nuestra Urteilskraft. ${ }^{12} \mathrm{Y}$ de ahí, asimismo, que lo sublime, en un sentido inequívocamente marioniano, resulte «inadecuado a nuestra facultad de exponer», es decir, de representar, objetivar y constituir un objeto en la medida en que se trata de una instancia claramente irregardable: que permite ser vista pero no contemplada desde una mirada constituyente. A pesar de la violencia, esto es, la "contra-experiencia», que impone a la imaginación, el fenómeno sublime deviene tal precisamente en virtud de su singular capacidad para contradecir, obstaculizar y violentar la totalidad de nuestras facultades cognoscitivas (tanto intuitivas como conceptuales) permitiéndonos a la vez continuar viéndolo: «manteniendo lo visible en su visibilidad, tanto como sea posible», apunta Marion.

\section{Conclusión}

El anterior examen de los cuatro rasgos esenciales que definen al fenómeno saturado pone de relieve el hecho de que cuando la intuición se expone a un elemento caracterizado por la sublimidad lo hace simultáneamente ante una paradoja. Tal vez radique aquí la razón que permite arrojar alguna luz sobre la renovada fascinación que la estética de lo sublime parece ejercer en múltiples dimensiones de la cultura contemporánea. En efecto, la crisis de la racionalidad tradicional que caracteriza a nuestra época parece convenir cumplidamente con el gusto por aquellos elementos que presentan esa capacidad para causar placer negativamente, al margen de todo concepto y merced a un acto de pura percepción dada con instantaneidad («sin razonar y sólo en la mera aprehensión») que Kant reconoce en lo sublime y que define, asimismo, al fenómeno saturado o paradójico.

\footnotetext{
${ }^{12}$ Así pues, como indica Tugba Ayas en referencia al origen de la experiencia de lo sublime: "Knowing that it does not have the authority to operate beyond sensibility, the faculty of imagination still strives towards its worldly limit trying to represent some object that it cannot represent [...]. In such a discomfort, reason comes forward and enables the imagination to extend itself (mathematically or dynamically) in order to represent what seems to be unattainable» (Ayas, 2013, 118).
} 
También, por ejemplo, los filmes de terror, tan del gusto de nuestra industria «cultural» y de un determinado sector del público más o menos amplio, fundamentan su aceptación en la cultura de masas merced a su capacidad para ocasionar en el espectador una suerte de "placer negativo" surgido de una cierta sobresaturación de la mirada (de ahí el característico gesto de «apartar la vista» de la pantalla en determinados momentos). «Placer negativo» no lejano al efecto producido tanto por la sublimidad kantiana como por el fenómeno saturado tan prolija y minuciosamente descrito por Marion. Como observa certeramente al respecto Michel Henry: «sucede que un mundo por naturaleza estético recibe la figura que le es propia en la época moderna: la de lo horrible y del horror» (Henry, 2006, 47). De este modo, aun de forma, si se quiere, distorsionada y dislocada, la sublimidad contemporánea parece erigirse en contrafigura de una racionalidad tradicional que, si bien era, desde luego, la kantiana, contenía ya larvadamente en su interior -al menos en lo referente a doctrinas como la de lo sublime- el germen de su reflejo especular en negativo.

\section{Bibliografía}

Aullón de Haro, P. (2006). La sublimidad y lo sublime. Madrid: Verbum.

Ayas, T. (2013). "Kant's notions of the sublime and cosmopolitanism in the 21 st century”, Filosofia Unisinos, 14 (2), pp. 113-127.

EAgleton, T. (20 i I). La estética como ideología, Madrid: Trotta.

GaEte Cáceres, M. A. (2015). "Ad infinitum: Implicaciones de lo sublime en la contemporaneidad", Fedro: revista de estética y teoría de las artes, No 14, pp. 36-50.

Heidegger, M. (2008). Preguntas fundamentales de la filosofia, Granada: Comares.

Henry, M. (2006). La barbarie, Madrid: Caparrós.

Kant, I. (1990). Crítica del juicio, Madrid: Espasa-Calpe.

-(1990b). Observaciones acerca del sentimiento de lo bello y de lo sublime, Madrid: Alianza.

Kuplen, M. (2015). "The Sublime, Ugliness and Contemporary Art: A Kantian Perspective, "Con-textos kantianos", No 1, pp. 114-141.

Lyotard, J.-F. (I99I). Leçons sur l'Analytique du sublime, Paris: Galilée.

Marion, J.-L. (2008). Siendo dado, Madrid: Síntesis.

- (2010). Le visible et le révélé, Paris: Cerf. 
Enviado: 29/09/2015

Aceptado: 9/12/2015

\section{(c) $(1) \Theta$}

ENDOXA está bajo una licencia de Creative Commons Reconocimiento-NoComercial-SinObraDerivada 4.0 Internacional 